\title{
Mathematical Modelling of Nitride Layer Growth of Low Temperature Gas and Plasma Nitriding of AISI 316L
}

\author{
A. Triwiyanto ${ }^{1, \mathrm{a}}$, A. Zainuddin ${ }^{1}$, K.A.Z Abidin ${ }^{1}$, M.A Billah ${ }^{1}$ and P.Hussain ${ }^{1}$ \\ ${ }^{1}$ Department of Mechanical Engineering, Universiti Teknologi Petronas, 31750, Malaysia
}

\begin{abstract}
This paper present mathematical model which developed to predict the nitrided layer thickness (case depth) of gas nitrided and plasma nitrided austenitic stainless steel according to Fick's first law for pure iron by adapting and manipulating the Hosseini's model to fit the diffusion mechanism where nitrided structure formed by nitrided AISI 316L austenitic stainless steel. The mathematical model later tested against various actual gas nitriding and plasma nitriding experimental results with varying nitriding temperature and nitriding duration to see whether the model managed to successfully predict the nitrided layer thickness. This model predicted the coexistence of $\varepsilon-\mathrm{Fe}_{2-3} \mathrm{~N}$ and $\gamma^{\prime}-\mathrm{Fe}_{4} \mathrm{~N}$ under the present nitriding process parameters. After the validation process, it is proven that the mathematical model managed to predict the nitrided layer growth of the gas nitrided and plasma nitrided of AISI 316L SS up to high degree of accuracy.
\end{abstract}

\section{Intoduction}

Austenitic stainless steel such as AISI 316L is widely used in several industrial applications, mainly due to its excellent corrosion resistance in different environment such as for food and chemical processing industries as well as in biomaterial applications. However, due to its inherent austenitic structure, this material has relatively low hardness as well as poor wear resistance which hinders a wider applicability of the material and may cause problems in existing applications. The gaseous thermochemical treatments would improve surface properties of this material which typically carried out in carbon and/or nitrogen bearing gases and usually associated with temperature above $500{ }^{\circ} \mathrm{C}$.

On the other hand, sensitization is occur where precipitation of chromium carbides $\left(\mathrm{Cr}_{23} \mathrm{C}_{6}\right)$ forms at the grain boundaries, typically between 450 to $850^{\circ} \mathrm{C}$; diffusional reaction in forming chromium nitride/carbide leads to the depletion of $\mathrm{Cr}$ in the austenitic solid solution and consequently unable to produce $\mathrm{Cr}_{2} \mathrm{O}_{3}$ passive layer to make stainless feature. As a result, this phenomenon causes reduction in ductility, toughness and aqueous corrosion resistance [1].

Bell et al. [2] suggested that a low temperature nitriding can avoid the formation of chromium nitrides but at the expense of strengthening effects made by $\mathrm{CrN}$ precipitates. Alternatively, the strengthening effect will be replaced by supersaturation of interstitial species in austenite matrix which leads to the hardening of the surface region several tens micro meter thick.

Recent work has shown that combination of nitriding-carburizing of austenitic stainless steel is

\footnotetext{
${ }^{a}$ Corresponding author : asmsceng@gmail.com
}

This is an Open Access article distributed under the terms of the Creative Commons Attribution License 2.0, which permits unrestricted use, distribution, and reproduction in any medium, provided the original work is properly cited. 
possible in plasma and gas furnace [3].

The objective of this work is to generate the mathematical modelling of nitrided layer thickness growth of AISI $316 \mathrm{~L}$ as a function of nitriding temperature and time. The mathematical model is then validated by comparing the calculated nitrided layer thickness versus the experimental nitrided layer thickness of different nitriding temperature and nitriding time.

\section{Methodology}

The mathematical model was developed by studying the model developed for the gas and plasma nitriding of pure iron by Hosseini et al (2007) [4]. After that, the model was manipulate to resemble the diffusion mechanism of gas and plasma nitriding of austenitic stainless steel. The mathematical model is then tested with different nitriding parameters based on experimental data gathered from various works to explore whether the mathematical model appropriate to predict the nitrided layer thickness of the gas nitrided or plasma nitrided austenitic stainless steel. If the mathematical model failed to predict the nitrided layer thickness, the whole steps is re-done in order to develop a more accurate mathematical model. According to Billion and Hendry (1985) [5], the expected nitrided layer growth structure for AISI 316L stainless steel are as per Figure 1.

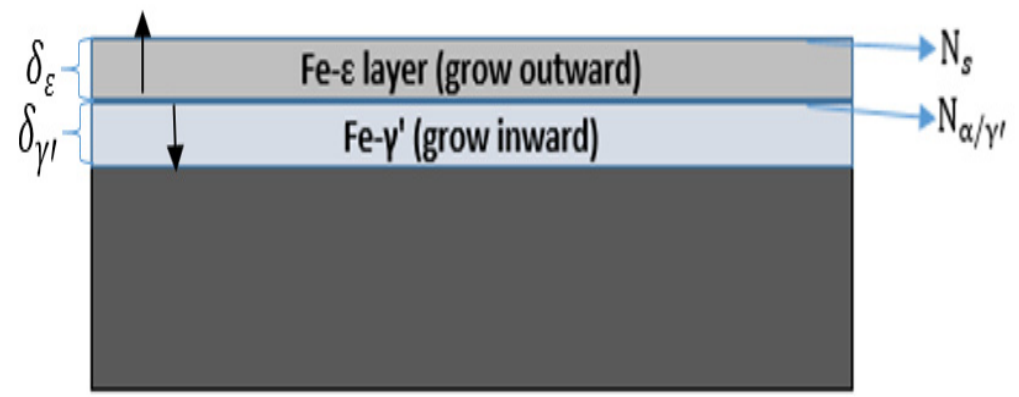

Figure 1. The nitride growth structure formed on the austenitic stainless steel.

\subsection{Mathematical Modelling for Predicting Nitrided Layer Thickness}

The mathematical model approach would use primarily according the Fick's first law for the nitriding process which can be expressed as Equation (1)

$$
J_{i}=-D_{i} \frac{\partial N_{i}(x, t)}{\partial x}, \text { where } i=\varepsilon \text { and } \gamma^{\prime}
$$

Therefore, the Fick's first law for nitrogen diffusion in each phase yields the following expression:

$$
J_{\varepsilon}=-D_{\varepsilon} \frac{\partial N_{\varepsilon}(x, t)}{\partial x}
$$

Where $J_{\varepsilon}$ is nitrogen fluxes, $D_{\varepsilon}$ is the diffusion coefficients of nitrogen, and $\mathrm{N}_{\varepsilon}$ is nitrogen concentrations in the $\varepsilon$ phase.

The mass conservation rule for the compound layers can be used in common with other investigation [6] indicate the results which is expressed in the following Equation 2.

$$
W_{\varepsilon} \frac{d \varepsilon}{d t}=\left[J_{\varepsilon}-J_{\gamma^{\prime}}\right] x=\lambda_{\varepsilon}
$$

Since the actual concentration are unknown, the following assumption of equilibrium is taken as per $\mathrm{Fe}-\mathrm{N}$ system (as per pure iron in Figure 1) since Fe is the main element in the austenitic stainless steel 
and has significant effect in the initial step as boundary conditions which can be expressed as per the following:

- Maximum concentration of nitrogen in $\varepsilon-\mathrm{Fe}_{2-3} \mathrm{~N}$ nitrides reaches $11.14 \mathrm{wt} \%$, when it is assumed as $\mathrm{Fe}_{2} \mathrm{~N}$ with a nitrogen content of 33.33 at\%. The concentration of nitrogen in this $\mathrm{Fe}_{2-3} \mathrm{~N}$ nitride is decreased to a minimum value of $7.71 \mathrm{wt} \%$ near the $\gamma^{\prime}$ interface, when it is assumed as $\mathrm{Fe}_{3} \mathrm{~N}$ including 25.0 at $\% \mathrm{~N}$.

- Concentration of nitrogen in $\gamma^{\prime}$ nitride is approximately equal to $5.9 \mathrm{wt} \%$, assuming to be the stoichiometric compound of $\mathrm{Fe}_{4} \mathrm{~N}$ with 20 at\% N. according to the data from literature [4], it is in the range of 5.76 to $5.90 \mathrm{wt} \%$.

Therefore by considering the boundary conditions I and II, the nitrogen concentration at interfaces between the $\varepsilon$ and $\gamma^{\prime}$ layers can be expressed as the following Equation 5 and Equation 6 .

$$
\begin{aligned}
& \mathrm{N}_{\varepsilon / \gamma^{\prime}} \approx 7.71 \mathrm{wt} \% \\
& \mathrm{~N}_{\gamma^{\prime} / \varepsilon} \approx 5.91 \mathrm{wt} \%
\end{aligned}
$$

On the other hand, the growth of compound layers follows a parabolic law which is expressed as

$$
\lambda_{i}=b_{i} \sqrt{t} \text { where } i=\varepsilon \text { and } \gamma^{\prime}
$$

where $\lambda_{i}, b_{i}$ and $\mathrm{t}$ are the thickness of $i$ layer, the constant of the growth rate and the nitriding time respectively. Derivation of the above equation would lead to these following equations:

$$
\frac{d \lambda_{i}}{d t}=\frac{b_{i}}{2 \sqrt{t}}
$$

\subsubsection{Calculating the $\varepsilon-F e_{2-3} N$ layer thickness}

Therefore by taking into account Equation (3), (7), and (8) can be arranged as

$$
\frac{0.9 b_{\varepsilon}}{\sqrt{t}}=\left[J_{\varepsilon}-J_{\gamma^{\prime}}\right] x=\lambda_{\varepsilon}
$$

The nitrogen concentration distribution in $\varepsilon$, calculated in the literature [9] and developed to the Equation 10

$$
N_{\varepsilon}=N_{s}+\frac{7.712-N_{s}}{\operatorname{erf}\left(\frac{\lambda_{\varepsilon}}{2 \sqrt{t D_{\varepsilon}}}\right)} \operatorname{erf}\left(\frac{x}{2 \sqrt{t D_{\varepsilon}}}\right)
$$

Where $\mathrm{N}_{\mathrm{S}}$ is the nitrogen concentration at the surface of the work piece as demonstrated in in three dimensional scales of the thickness of epsilon nitride versus $\mathrm{K} \varepsilon$ and nitriding time at constant nitriding temperature, $550^{\circ} \mathrm{C}[6]$. According to this the derivation and simplification of the above equation yields nitrogen flux at the interface between the $\varepsilon$ and $\gamma^{\prime}$ nitride as Equation 11

$$
\left.J_{\varepsilon}\right|_{x=\lambda \varepsilon} \mid \approx 3.4 \frac{D_{\varepsilon}}{\lambda_{\varepsilon}}
$$

On the other hand, nitrogen concentration distribution in $\gamma^{\prime}$ layer can be calculated by the Equation 12 and yield nitrogen flux of Equation 13 [4].

$$
N_{\gamma^{\prime}}=\frac{0.14 \lambda_{\varepsilon}+5.9 \lambda_{\gamma^{\prime}}}{\lambda_{\gamma^{\prime}}}-\frac{0.28 \sqrt{T D_{\gamma^{\prime}}}}{\lambda_{\gamma^{\prime}}} \operatorname{erf}\left(\frac{x}{2 \sqrt{t D_{\gamma^{\prime}}}}\right)
$$




$$
J_{\gamma^{\prime}}=0.14 \frac{D_{\gamma^{\prime}}}{\lambda_{\gamma^{\prime}}}
$$

\subsubsection{Calculation of $y^{\prime}$ nitride thickness}

For the calculation of $\gamma^{\prime}$ nitride thickness, we take into the consideration the nitrogen concentration on the surface as per Equation 2. Same process as per calculation of $\varepsilon-\mathrm{Fe}_{2-3} \mathrm{~N}$ layer which yield the following equation.

$$
\lambda_{\gamma^{\prime}} \approx 0.5\left[-\left(b_{\varepsilon}+0.02 \sqrt{D_{\alpha}}\right)+\sqrt{\left(b_{\varepsilon}+0.02 \sqrt{D_{\alpha}}\right)^{2}+0.2 D_{\gamma^{\prime}}}\right] \cdot \sqrt{t}
$$

\subsubsection{Calculating the diffusion coefficients according to Karabelchtchikova approach [6]}

$$
D_{\varepsilon}=2.1 \times 10^{-8} \exp \left[\frac{-93517 \frac{\mathrm{J}}{\mathrm{mol}}}{8.314 T \frac{\mathrm{J}}{\mathrm{mol} . \mathrm{K}}}\right]
$$

\subsection{Conclusion for the mathematical model}

As mentioned earlier, the mathematical model for total nitrided layer growth of austenitic stainless steel must account for the $\gamma^{\prime}$ nitride thickness and $\varepsilon-\mathrm{Fe}_{2-3} \mathrm{~N}$ layer thickness. Therefore, the total thickness of the nitrided layer growth below the surface is the addition of $\gamma^{\prime}$ nitride thickness and $\varepsilon$ $\mathrm{Fe}_{2-3} \mathrm{~N}$ layer thickness. Total thickness for nitride layer growth $=\lambda \gamma^{\prime}+\lambda \mathrm{s}$, Where

$$
\lambda_{\varepsilon}=\sqrt{\left(4 D_{\varepsilon}-0.2 D_{\gamma^{\prime}}\right) t}
$$

\section{The Results of Comparison Layer Thickness from The Calculated (as predicted) Versus the Experimental}

In order to test the validity of the equations, the author make a comparison between the calculated nitride layers thickness versus the actual experimental thickness based on experiments conducted by Dr. Patthi [7] and K. Subramanian and N.T. Ansari [8] for gas nitriding of AISI 316L SS and experiments conducted by N. Revenier et al. [9], A. Fossati et al. [10] and Tsujikawa et al. [11] for plasma nitriding of AISI 316L SS.

The results of the comparison was very promising, especially in predicting the nitrided layer thickness of plasma nitrided AISI 316L SS. This is due to the fact that the mathematical model managed to predict the nitrided layer thickness of the plasma nitrided AISI $316 \mathrm{~L}$ up to $\pm 8 \mu \mathrm{m}$ (the largest difference in the calculated thickness versus the experimental thickness recorded) for plasma nitrided AISI 316L SS. However, this is not the case for gas nitrided AISI 316L where the largest recorded difference in the calculated thickness versus the experimental thickness was at $0.037 \mathrm{~mm}$. However, in general, the mathematical model managed to predict the nitrided layer thickness of AISI 316L SS up to a good accuracy for both plasma nitriding and gas nitriding of AISI 316L stainless steel. The summary of the calculated nitrided layer thickness versus the experimental thickness for gas AISI 316L SS are shown in the Table 1 and Table 2 for the its plasma nitrided counterparts.

Based on the comparison data from all experiments conduted by [7] and [8], the large difference in thickness between the measured and calculated nitrided thickness was calculated to be the largest at $0.037 \mathrm{~mm}$ while the others were in the range of 0.015 to $0.019 \mathrm{~mm}$ which accounts for $4 / 11$ of the 
total possible cases. Therefore, this shows that the mathematical model manage to predict the nitrided layer thickness for gas nitrided AISI 316L SS fairly.

Based on comparison data from all experiments conduted by [9] and [11], the largest difference in thickness between the measured and calculated nitrided thickness was calculated to be at $0.0077 \mathrm{~mm}$ which is very small indicating that the mathematical model manage to predict the nitrided layer thickness of the plasma nitrided layer thickness of AISI 316L SS up to great accuracy.

\section{Conclusion}

With respect to the gas nitrided AISI 316L SS, the difference between the measured and calculated nitrided thickness was calculated to be the largest at $0.037 \mathrm{~mm}$ while the others were in the range of 0.015 to $0.019 \mathrm{~mm}$ which accounts for $4 / 11$ of the total possible points. Therefore, this shows that the mathematical model managed to predict the nitrided layer thickness for gas nitrided AISI 316L SS fairly given by the facts that the other $7 / 11$ other readings indicates that the mathematical model managed to accurately predict the gas nitrided layer thickness of AISI 316L SS.

On the other hand, for plasma nitrided AISI 316L SS, the difference in thickness between the measured and calculated nitrided thickness was calculated to be largest at $0.0077 \mathrm{~mm}$ which is relatively very small indicating that the mathematical model managed to predict the nitrided layer thickness of the plasma nitrided layer thickness of AISI 316L SS up to great accuracy.

In conclusion, the mathematical model successfully managed to predict the plasma nitrided layer thickness of AISI 316L SS which was shown in the experimental works in [9] and [11] and also managed to fairly predict the gas nitrided layer thickness of AISI 316L SS which was described according experimental works done in [7] and [8].

\section{References}

1. Clark. D.S. and Varney. W.R., Physical Metallurgy for Engineers, Litton educational publishers, (1962)

2. T. Bell and Y. Sun, Stainless Steel 2000, Maney Publ., London, (2001)

3. A. Triwiyanto., et.al, Journal of Applied Sciences, 11(9), 1536 -1543, (2011)

4. S.R. Hosseini, A. Kermanpur \& F. Ashrafizadeh, Iranian Journal of Science and Technology, Transaction B, 34 (B5) 553-566, (2010)

5. B. Billion and A. Hendry, Surface Engineering Journal. 1(114), (1985)

6. Karabelchtchikova, O., "Fundamentals of Mass Transfer in Gas Carburizing," PhD Dissertation, Worcester Polytechnic Institute, (2007)

7. P. Hussain, "Diffusion of sialon and stainless steel", $\mathrm{PhD}$ dissertation, Dept. mechanical engineering, University of Strathclyde, United Kingdom, (1997)

8. K. Subramaniam and N.T. Ansari, "Surface hardening of $316 \mathrm{LN}$ grade austenitic stainless steel using gas nitriding process", thesis for bachelor in engineering, S.R.M Engineering College, Kattankulathur, Anna University, Chennai, India, (2006)

9. N. Renevier. P. Collignon, H. Michel, T. Czerwiec, Surface and Coatings Technology, 11, 128133 (1999)

10. A. Fossati, F. Borgioli, E. Galvanetto, T. Bacci, Surface \& Coatings Technology, 200, 3511-3517, (2006)

11. M. Tsujikawa, D. Yoshida, N. Yamauchi, N. Ueda, T. Sone, and S.Tanaka, Surface \& Coatings Technology, 200 507-511, (2005) 